Revista Destaques Acadêmicos, Lajeado, v. 9, n. 1, 2017. ISSN 2176-3070 DOI: http://dx.doi.org/10.22410/issn.2176-3070.v9i1a2017.1145 www.univates.br/revistas

\title{
PLANEJAMENTO FINANCEIRO - DE PAI PARA FILHO: UM ESTUDO COM OS PAIS DE ALUNOS DO ENSINO FUNDAMENTAL
}

\author{
Elaine Lassen Bayer ${ }^{1}$, Gabriel Machado Braido²
}

Resumo: Este artigo tem como objetivo analisar se os pais dos alunos do ensino fundamental (primeiro ao nono ano), de uma escola de ensino particular do município de Teutônia/RS, planejam o futuro financeiro de seus filhos e de que maneira este planejamento se dá. Para o desenvolvimento deste estudo, o método utilizado teve uma abordagem descritiva e quantitativa. Como resultado, identificou-se um perfil de pais conscientes sobre a importância do planejamento financeiro e a existência de um planejamento do futuro financeiro de seus filhos.

Palavras-chave: Planejamento financeiro. Finanças pessoais. Educação financeira. Educação previdenciária. Instituição de Ensino Fundamental.

\section{INTRODUÇÃO}

Atualmente, vive-se em um cenário econômico de grande crise, cheio de incertezas. Nessas circunstâncias, o planejamento financeiro torna-se imprescindível para a da saúde financeira das pessoas e famílias como um todo.

Conforme Luxo (2016), o que se percebe é que atualmente a maior parte das famílias brasileiras tem o péssimo hábito de gastar mais do que recebe, não faz orçamento familiar e acaba tendo despesas mensais com taxas de juros exorbitantes. Fazer a gestão das finanças pessoais e familiares é essencial para se ter uma melhor qualidade de vida, hoje e amanhã.

Desde criança, a orientação que os pais passam para seus filhos é sobre o desenvolvimento de habilidades como comer, falar e andar, no entanto não educam seus filhos para lidar com dinheiro e orçamento familiar. Acredita-

1 Bacharel em Direito (Unisinos) e Especialista em Gestão Empresarial (Univates). É gerente de relacionamento do Banco do Brasil, Agência Empresarial Santa Cruz do Sul. elainelassen@gmail.com

2 Doutorando (Unisinos), Mestre (UFRGS) e Bacharel em Administração (Univates). É professor assistente do Centro Universitário UNIVATES - Lajeado/RS. gabrielb@univates.br 
se que nos tempos atuais, as crianças e adolescentes desconhecem o custo de manutenção de uma casa, quanto se gasta com água, luz, alimentação, transporte e educação.

Além do fato de fazer parte da natureza humana, a propensão de acumular bens, muitas vezes desnecessários, como mais roupas e sapatos do que conseguem usar, mais comida na geladeira do que necessariamente vai ser consumida, gera um desperdício de dinheiro, pois grande parte destas roupas e calçados nunca serão usados e os alimentos estragarão antes do consumo.

Este artigo tem por objetivo identificar como é que os pais dos alunos do primeiro ao nono ano do Ensino Fundamental do Colégio Teutônia veem a importância do planejamento financeiro de seus filhos.

Espera-se, com este trabalho, demonstrar para os pais que as novas gerações devam ser educadas financeiramente para que este instinto consumista seja travado. Quando não há um planejamento financeiro, muito se perde ao longo da vida. Se a vida financeira das pessoas é organizada, destinando sua renda para o pagamento das despesas mensais e parte para uma reserva econômica, é possível visualizar quanto de sua renda pode ser disponibilizada para a aquisição de um bem, como um veículo ou o pagamento da faculdade, por exemplo.

Hoje as escolas já estabelecem em seu conteúdo didático a introdução à educação financeira. Desde cedo, trabalha-se nas disciplinas escolares de que maneira as crianças podem e devem participar na construção do orçamento familiar.

Pensando nisto, optou-se por realizar este trabalho de pesquisa junto aos pais dos alunos do ensino fundamental, do primeiro ao nono ano, a fim de identificar como os pais veem e planejam o futuro financeiro de seus filhos. A pesquisa foi aplicada em uma instituição de ensino particular, de classe média alta, localizada no município de Teutônia/RS.

A pesquisa abrange também as crianças do primeiro ano, a partir dos seis anos, pois entende-se que quanto antes se pensar no futuro dos filhos, e se agir para tanto, antes pode-se começar de uma maneira que não seja tão onerosa, uma vez que o tempo de contribuição é bastante longo.

Ademais, a previdência social brasileira, que tem por objetivo proporcionar meios de subsistência aos seus segurados e beneficiários após a aposentadoria, vem enfrentando sérias dificuldades e incertezas para seus contribuintes nos dias atuais.

Estas dificuldades tendem a aumentar com o passar dos anos, em razão do aumento da expectativa de vida dos contribuintes e a diminuição da composição das famílias brasileiras, devido à redução da natalidade.

Portanto, daqui a alguns anos, a população brasileira será composta de muitos aposentados usufruindo dos benefícios e sem qualquer contribuição 
à previdência social e um número reduzido de trabalhadores contribuintes para sustentar o sistema. Por este motivo, os pais têm, cada vez mais cedo, de preocupar-se com o futuro de novas gerações.

O artigo está estruturado da seguinte maneira: o segundo capítulo apresenta o referencial teórico consultado para realização da pesquisa; os procedimentos metodológicos utilizados são descritos no terceiro capítulo, após há a apresentação e discussão dos resultados, no capítulo quarto; por fim apresenta-se as considerações finais referentes ao estudo no quinto capítulo.

\section{REFERENCIAL TEÓRICO}

Neste capítulo são apresentados os principais conceitos consultados para a realização dessa pesquisa, compreendendo os tópicos de planejamento financeiro, finanças pessoais, educação financeira e educação previdenciária.

\subsection{Planejamento financeiro}

Em tempos em que a economia vem sofrendo variações e está suscetível a fatores globais, ter um planejamento financeiro é uma ferramenta de grande valia para decisões serem tomadas. Planejar é traçar um caminho, conhecer suas rotinas financeiras e colocar na ponta do lápis suas receitas e despesas.

Segundo Ross, Westerfiel e Jaffe (1995), o planejamento financeiro é um aspecto importante das operações nas empresas e famílias, pois esse plano mapeia os caminhos para guiar, coordenar e controlar suas ações para atingir seus objetivos. Para os autores, a partir do planejamento financeiro é possível visualizar com antecedência as possibilidades de investimento, o grau de endividamento e o montante de dinheiro que pode ser deixado disponível, visando seu crescimento e respectiva rentabilidade. Esta ideia pode ser aplicada tanto para as empresas como para planejamento pessoal.

O planejamento financeiro deve sempre considerar atitudes a serem tomadas e suas consequências, tanto por indivíduos e famílias, quanto por empresas, o que requer pensamento estratégico, questionamentos e reflexões sobre objetivos e metas.

Planejamento financeiro é um processo que administra rendas, investimentos, patrimônio, despesas e dívidas, a racionalização dos gastos e a otimização de recursos financeiros.

Conforme descrevem Lemes Jr., Cherobim e Rigo (2002) o processo de planejamento financeiro, seja de ordem empresarial ou pessoal, apresenta-se como uma importante ferramenta para a estratégia e administração financeira, pois oferece condições para formular a política de crescimento e outorgar sustentação financeira de suas atividades sem colocar em risco as finanças, contribuindo significativamente para o crescimento profissional e pessoal. 
Deve-se enfatizar que o planejamento e o controle estão diretamente ligados. Para Weston e Brighan (2000), o planejamento é necessário para a fixação de padrões e metas, enquanto que o controle permite obter informações e comparar os planos com os desempenhos reais, e fornecer subsídios para a realização de um processo de feedback no qual o sistema pode ser transformado para que alcance a situação desejada.

\subsection{Finanças pessoais}

No dia a dia, pessoas e famílias precisam tomar decisões financeiras que impactam em suas vidas pessoais. Através das finanças pessoais, é possível observar como os indivíduos e as famílias administram sua renda.

Conforme descreve Gitman (2010), o primeiro passo para o planejamento financeiro pessoal é definir suas metas. Enquanto uma empresa objetiva maximizar a riqueza de suas ações, as pessoas normalmente têm diversos objetivos importantes. De um modo geral, as metas pessoais podem ser de curto prazo (um ano), médio prazo (dois a cinco anos), ou longo prazo (seis anos ou mais).

Ainda conforme o autor, devem ser estabelecidas metas financeiras de curto e longo prazo e devem ser desenvolvidos planos financeiros pessoais que mostrem o caminho para chegar aos objetivos. Os planos financeiros de curto e longo prazo devem estar alinhados, uma vez que para alcançar os objetivos de longo prazo, os de curto prazo devem estar estabelecidos. Os fluxos de caixa e os planos financeiros são tão importantes para os indivíduos quanto para as empresas.

Segundo Matsumoto et al. (2013) existem quatro passos para um bom planejamento financeiro pessoal, que seguem:

$1^{\circ}$ passo - Reunir a família para analisar a situação financeira e fixar metas. É importante que a família estabeleça um plano de metas, dizendo em que precisa investir seu dinheiro a curto, médio e longo prazo.

$2^{\circ}$ passo - Anotar as despesas/separar o dinheiro. Definidas as metas, o próximo passo é anotar durante um mês, diariamente, tudo o que se gastou. É bom reservar cinco minutos do dia para fazer isto. É um ritual que pode ajudar a apontar os excessos e as mudanças que podem ser feitas.

$3^{\circ}$ passo - Elaborar o orçamento doméstico. Conhecidas as despesas mensais, o próximo passo é elaborar um orçamento mensal, podendo assim, chegar a alguns resultados que poderão ser analisados para futuras providências.

$4^{\circ}$ passo - Comparar as despesas reais com o orçamento realizado. Comparando as despesas reais com o orçamento realizado, podendo-se verificar três situações:

- Ganhos superiores aos gastos; 
- Ganhos iguais aos gastos (equilíbrio);

- Ganhos inferiores aos gastos.

A primeira situação é a que possibilita ao cidadão dispor de reserva financeira. O ideal é que a pessoa seja capaz de guardar aproximadamente $20 \%$ (vinte por cento) do que ganha.

Na segunda situação qualquer centavo economizado vira lucro para poder gastar com outras compras ou mesmo aumentar o saldo de sua poupança. É fundamental saber administrar bem o orçamento doméstico e reaprender o valor de cada produto ou serviço.

Na terceira situação verifica-se a necessidade de se adotar diferentes procedimentos como reduzir as despesas e/ou aumentar as receitas.

Para o Serasa Experian (2012), planejamento financeiro pessoal significa ordenar a vida financeira de tal maneira que se possa sempre ter reservas para imprevistos da vida e, sistemática e vagarosamente, construir um patrimônio (financeiro e imobiliário) que garanta, na aposentadoria, fontes de renda suficientes para uma vida tranquila e confortável.

\subsection{Educação financeira}

Segundo Gadelha e Lucena (2015), educação financeira é uma ferramenta indispensável aos resultados na gestão financeira, em que promove o desenvolvimento de competências para controlar, planejar, analisar e simular as informações financeiras necessárias para as tomadas de decisões.

A educação financeira não consiste apenas em aprender a economizar, cortar gastos desnecessários, poupar e acumular economias, mas também, funciona como uma ferramenta utilizada na busca de uma melhor qualidade de vida hoje e no futuro, com o intuito de proporcionar uma aposentadoria mais tranquila para que seja possível desfrutar as coisas boas da vida, com reservas para quaisquer imprevistos que possam ocorrer.

Conforme Pinheiro (2008), por meio da educação financeira os indivíduos e as sociedades têm melhor compreensão dos produtos financeiros, e, por consequência, desenvolvem os valores e competências necessários para uma melhor compreensão das oportunidades e riscos neles envolvidos. A educação financeira tem por objetivo estimular o consumo consciente, ou seja, o consumo sabedor dos riscos e benefícios, com base em necessidades reais das pessoas e famílias.

Para Gianetti (2005), segundo o conceito de trocas intertemporais, há duas maneiras de se obter bens: poupar hoje e comprar à vista no futuro ou comprar hoje, financiando o bem, e pagá-lo com juros no futuro. Não se pode afirmar que uma ou outra opção é a que está correta, pois depende do benefício que o bem a ser adquirido trará agora ou no futuro e da capacidade de pagamento da pessoa que o está adquirindo, no momento ou no futuro. 
Conforme Greesnspan (2002), a Educação Financeira pode ser muito útil aos indivíduos, no sentido de dotá-los com conhecimento financeiro necessário para elaborar orçamentos, iniciar planos de poupança e fazer investimentos estratégicos, auxiliando na tomada de decisões. O planejamento financeiro pode ajudar as famílias a cumprir suas obrigações a curto e a longo prazo, e maximizar seu bem-estar, e é especialmente importante para as populações que têm sido tradicionalmente subatendidas pelo nosso sistema financeiro.

\subsection{Educação Previdenciária}

Entende-se a educação previdenciária como sendo a educação financeira com foco nas questões previdenciárias. Estes dois termos referentes à educação estão associados, pois a educação previdenciária é uma vertente da educação financeira.

Conforme Pinheiro (2008), os fatores que se destacam nas ações de educação previdenciária são a carência da cultura de poupança à longo prazo do país, o envelhecimento populacional, a complexidade dos termos e conceitos relacionados ao setor previdenciário, a tendência na migração dos planos de aposentadoria da modalidade de benefício definido para os planos de benefícios nas modalidades de contribuição definida e mista e o alto nível de responsabilidade exigida pelos fundos de pensão.

A cultura brasileira é imediatista, ou seja, opta-se por usufruir de seu investimento no momento em que se paga por ele, como por exemplo, a aquisição de um veículo ou de um imóvel. Uma poupança ou uma previdência privada, que possuem retorno a longo prazo, são pouco atrativas para a população, pois o recurso investido só poderá ser usufruído no futuro.

Conforme o curso Orientação Financeira em Negócios Bancários, da Universidade Banco do Brasil - UNIBB, no Brasil e em diversos países, o envelhecimento populacional é uma questão preocupante. $\mathrm{O}$ aumento da expectativa de vida, através da redução da mortalidade das populações com idades mais avançadas, aumentará a pressão nos orçamentos governamentais, devido ao método de pagamento utilizado pelo sistema de seguridade social, em que as contribuições atuais são utilizadas para o pagamento do benefício das pessoas já aposentadas.

Por consequência, as pessoas terão que financiar uma parcela cada vez maior de sua aposentadoria. Portanto, deverão planejar suas finanças para garantir o nível de renda suficiente para manter o padrão de vida que desfrutavam na fase laboral. O ideal seria que, depois de tantos anos de trabalho, as pessoas pudessem manter o mesmo padrão de vida que tinham quando estavam na ativa.

Também, com base no curso Orientação Financeira em Negócios Bancários, constata-se que é por meio de informações, instruções e orientações que se desperta e provoca atitudes proativas nas pessoas no que diz respeito 
à previdência complementar. Ter uma previdência complementar faz toda a diferença na hora de planejar o futuro para a manutenção da renda na hora da aposentadoria. A previdência complementar é privada e pode ser aberta, para fins lucrativos e é acessível a todos os cidadãos; ou fechada, também conhecida como Fundos de Pensão, que não tem fins lucrativos e é restrita a funcionários de uma empresa ou membros de uma associação de classe.

A previdência complementar aberta e a fechada têm pontos em comum. A filiação não é obrigatória e não depende da previdência pública. $O$ benefício de aposentadoria é pago com base nas reservas acumuladas no decorrer dos anos e é adicional ao benefício pago pela previdência social, de acordo com o curso Orientação Financeira em Negócios Bancários.

\section{PROCEDIMENTOS METODOLÓGICOS}

Conforme Severino (2007), o elemento principal utilizado no processo do conhecimento pela ciência é o método científico.

Segundo Marconi e Lakatos (2002), método é o conjunto de atividades sistemáticas e racionais que permitem alcançar o objetivo da pesquisa com maior economia e segurança, apontando caminhos a serem seguidos e embasando a tomada de decisões do pesquisador (MARCONI; LAKATOS, 2002).

Para alcançar o objetivo apontado por este estudo, foi realizado um estudo descritivo, com abordagem quantitativa, utilizando-se o levantamento como procedimento técnico. Este trabalho é classificado como descritivo, pois segundo Barros e Lehfeld (2000), neste tipo de estudo o pesquisador apenas descreve o objeto da pesquisa. Neste sentido, a pesquisa teve como objetivo identificar se as famílias dos estudantes de $1^{\circ}$ ao $9^{\circ}$ ano do Ensino Fundamental do Colégio Teutônia, da comarca de Teutônia, planejam o futuro financeiro de seus filhos.

Relativo à abordagem metodológica, a pesquisa é classificada como quantitativa, pois conforme Nique e Ladeira (2014), este tipo de pesquisa tem como característica o emprego de técnicas estatísticas, com cálculos matemáticos para a coleta e análise dos dados. A pesquisa aplicada é considerada quantitativa, pois utilizou instrumentos que permitiram a quantificação do objeto do estudo. As informações foram colhidas por meio de um questionário estruturado com perguntas claras e objetivas. Utilizou-se uma amostra representativa com o objetivo de quantificar se os pais dos alunos do Ensino Fundamental do Colégio Teutônia planejam o futuro financeiro de seus filhos.

Referente aos procedimentos técnicos, utilizou-se um levantamento, que conforme Gil (2002), é caracterizado pela interrogação direta das pessoas envolvidas nas pesquisas, cujo comportamento deseja-se conhecer. Dessa forma, pesquisou-se em um grupo significativo de famílias sobre o problema em estudo, para que através de uma análise quantitativa, fosse possível obter conclusões sobre os dados coletados. 
A população em estudo foram famílias de estudantes matriculados do $1^{\circ}$ ao $9^{\circ}$ ano do Ensino Fundamental do Colégio Teutônia, comarca de Teutônia/ RS, onde foram aplicados 272 questionários, dos quais 111 foram respondidos e validados. O questionário, com 20 questões, foi elaborado segundo os questionários propostos por Almeida (2010), Barros (2010) e Zenker (2012), com perguntas claras e objetivas de até cinco opções de resposta, ou opção de sim ou não.

Antes de iniciar a pesquisa, realizou-se a validação com dois professores especialistas da área financeira que validaram o proposto no questionário. Após, realizou-se um pré-teste com duas famílias escolhidas por conveniência, que corroboraram nas questões propostas, sem apresentar sugestões de melhorias.

Segundo Malhotra (2001), o pré-teste é utilizado para avaliar a forma e verificar a elaboração das perguntas, sua sequência, formato, layout e se quem está respondendo o questionário compreendeu as perguntas propostas.

Conforme Marconi e Lakatos (2002), o objetivo do pré-teste é verificar possíveis falhas existentes no questionário. Após o pré-teste, o questionário foi aplicado em todas as turmas do Ensino Fundamental do Colégio Teutônia, no mês de agosto de 2016, depois foram tabulados e analisados com o auxílio do Software Excel. O questionário foi enviado para as famílias pelo Colégio Teutônia, pelos alunos de cada turma e recolheu os questionários que foram respondidos pelos pesquisados.

Os resultados, para melhor visualização, serão apresentados em forma de tabelas e gráficos na seção seguinte. A tabela é um meio preciso para se apresentar os resultados, facilitando a compreensão e a interpretação dos dados, segundo Andrade (2003).

Como limitações ao estudo, ressalta-se que os resultados apresentados não podem ser generalizados, sendo válidos apenas para as famílias dos estudantes do Ensino Fundamental do Colégio Teutônia, comarca de Teutônia, no estado do Rio Grande do Sul.

Após a apresentação dos procedimentos metodológicos utilizados na realização desta pesquisa, no próximo capítulo serão apresentados os resultados do estudo.

\section{APRESENTAÇÃO E DISCUSSÃO DOS RESULTADOS}

Neste capítulo são apresentados e discutidos os resultados obtidos com a realização desta pesquisa. O capítulo está estruturado em três seções, compreendendo o perfil dos respondentes, questões de conhecimento sobre finanças pessoais e educação financeira e por último planejamento financeiro e educação previdenciária. 


\subsection{Perfil dos respondentes}

Para um melhor conhecimento dos participantes da amostra pesquisada, na primeira seção elencou-se questões referentes ao sexo, estado civil, renda dos participantes, grau de instrução e número de filhos. Dos 111 entrevistados, $65,77 \%$ são do sexo feminino e $34,23 \%$ são do sexo masculino. No que se refere ao estado civil, pela Tabela 1, a maioria dos entrevistados é casada, com 82,88\%.

Tabela 1 - Estado Civil

\begin{tabular}{lccc}
\hline & Frequência & Porcentagem & Porcentagem Acumulada \\
\hline Solteiro & 10 & $9,01 \%$ & $9,01 \%$ \\
Casado & 92 & $82,88 \%$ & $91,89 \%$ \\
Separado Jud/Divorciado & 7 & $6,31 \%$ & $98,20 \%$ \\
Viúvo & 1 & $0,90 \%$ & $99,10 \%$ \\
Não respondeu & 1 & $0,90 \%$ & $100,00 \%$ \\
\hline TOTAL & $\mathbf{1 1 1}$ & $\mathbf{1 0 0 , 0 0 \%}$ & \\
\hline
\end{tabular}

Fonte: dos autores.

Na tabela 2, observa-se a renda salarial dos entrevistados. Nota-se que o maior percentual está acima de 02 até 04 salários mínimos, com 27,03\%, seguidos por de até 02 salários mínimos com $21,62 \%$ e depois pela faixa de acima de 08 salários com 18,92\%, seguido por acima de 04 até 06 salários mínimos com $16,22 \%$ e, por fim, acima de 06 até 08 salários com $11,71 \%$. 4,5\% não responderam. As rendas estão bem distribuídas em todas as faixas salariais.

Tabela 2 - Renda Familiar

\begin{tabular}{lccc}
\hline & Frequência & Porcentagem & Porcentagem Acumulada \\
\hline Até 02 Salários Mínimos & 24 & $21,62 \%$ & $21,62 \%$ \\
Acima de 02 até 04 SM & 30 & $27,03 \%$ & $48,65 \%$ \\
Acima de 04 até 06 SM & 18 & $16,22 \%$ & $64,87 \%$ \\
Acima de 06 até 08 SM & 13 & $11,71 \%$ & $76,58 \%$ \\
Acima de 08 Sal. Mínimos & 21 & $18,92 \%$ & $95,50 \%$ \\
Não respondeu & 5 & $4,50 \%$ & $100,00 \%$ \\
\hline TOTAL & $\mathbf{1 1 1}$ & $\mathbf{1 0 0 , 0 0 \%}$ \\
\hline
\end{tabular}

Fonte: dos autores. 
Observando-se a Tabela 3, constata-se que o grau de instrução dos respondentes com maior percentual é o Ensino Superior Completo com 27,93\%, seguido da Pós-Graduação Completa com 22,52\%.

Tabela 3 - Grau de Instrução

\begin{tabular}{lccc}
\hline & Frequência & Porcentagem & Porcentagem Acumulada \\
\hline $\begin{array}{l}\text { Ensino Fundamental In- } \\
\text { completo }\end{array}$ & 4 & $3,60 \%$ & $3,60 \%$ \\
$\begin{array}{l}\text { Ensino Fundamental Com- } \\
\text { pleto }\end{array}$ & 3 & $2,70 \%$ & $6,30 \%$ \\
Ensino Médio Incompleto & 2 & $1,80 \%$ & $8,10 \%$ \\
Ensino Médio Completo & 22 & $19,82 \%$ & $27,92 \%$ \\
Ensino Superior Incom- & 13 & $11,71 \%$ & $39,63 \%$ \\
pleto & 31 & $27,93 \%$ & $67,56 \%$ \\
Ensino Superior Completo & 6 & $5,41 \%$ & $72,97 \%$ \\
Pós-Graduação Incom- & 25 & $22,52 \%$ & $95,49 \%$ \\
pleto & 5 & $4,51 \%$ & $100,00 \%$ \\
Pós-Graduação Completa & $\mathbf{1 1 1}$ & $\mathbf{1 0 0 , 0 0 \%}$ & \\
Mestrado/Doutorado & & & \\
\hline TOTAL & 5 & & \\
\hline
\end{tabular}

Fonte: dos autores.

Com relação ao questionamento sobre a quantidade de filhos o maior índice ficou com 2 filhos, 50,45\% dos entrevistados, seguido por 1 filho com $41,44 \%$. O percentual de 3 filhos completou a pesquisa com $8,11 \%$.

Tabela 04 - Número de filhos

\begin{tabular}{ccccc}
\hline & & Frequência & Porcentagem & Porcentagem Acumulada \\
\hline 1 & 46 & $41,44 \%$ & $41,44 \%$ \\
& 2 & 56 & $50,45 \%$ & $91,89 \%$ \\
\hline TOTAL & 9 & $8,11 \%$ & $100,00 \%$ \\
\hline
\end{tabular}

Fonte: dos autores.

\subsection{Finanças Pessoais e Educação Financeira}

Para Folkus e Graci (1989), finanças pessoais é uma ciência que estuda os conceitos financeiros transmitidos a um indivíduo, com o intuito de que ele aplique estes conhecimentos quando for tomar decisões, a fim de que mantenha um comportamento equilibrado de seus orçamentos perante o mercado 
financeiro. Observa-se que quando as pessoas planejam suas finanças pessoais, veem a necessidade de destinar recursos para a satisfação de suas necessidades básicas e de desejos de consumo.

A segunda seção de questões refere-se às finanças pessoais e educação financeira, em que se buscou identificar junto às famílias pesquisadas o seu conhecimento sobre finanças e a importância da educação financeira para com seus filhos.

No Gráfico 1 que segue, os respondentes foram instruídos a informar sobre seu conhecimento em finanças em uma escala de 1 a 5 , onde 1 representa não possui conhecimentos em finanças e 5 representa possuo sólidos conhecimentos em finanças. A maior concentração de respostas foi 4 com $47 \%$ e $3 \mathrm{com} 33 \%$. A média de conhecimentos em finanças dos respondentes ficou em 3,56 .

Gráfico 1 - Como você avalia o seu conhecimento sobre finanças?

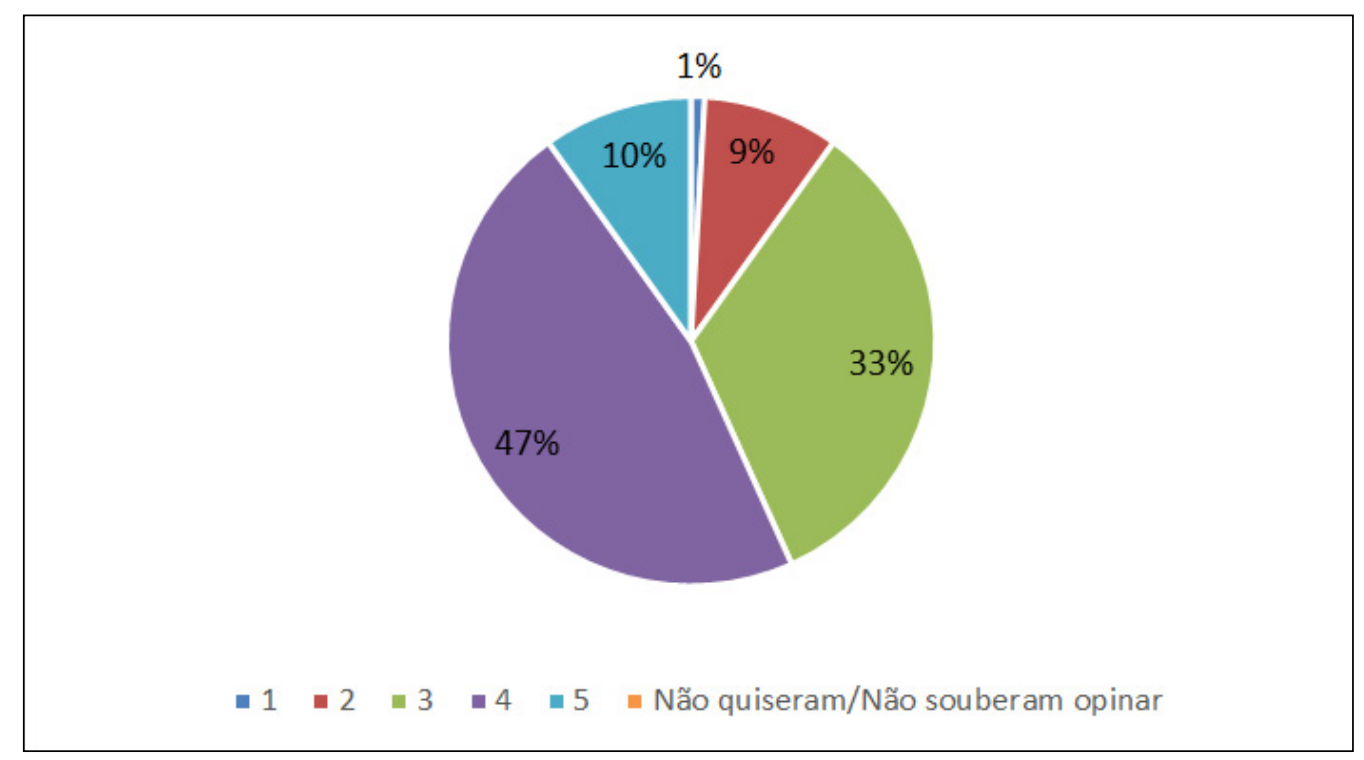

Fonte: dos autores.

Na questão seguinte, foi pedido aos respondentes que afirmaram ter conhecimento em finanças sobre como adquiriram esse conhecimento. Nessa pergunta, os pesquisados responderam mais de um quesito. $\mathrm{O}$ total de respostas foi de 148 e o item com maior percentual foi no trabalho, com $49 \%$, seguido de faculdade com $21 \%$ e cursos técnicos com $14 \%$. Escola foi apontada por $10 \%$ dos pesquisados e amigos e não responderam com $3 \%$ cada. 
Gráfico 2 - Se tem conhecimento em finanças como aprendeu?

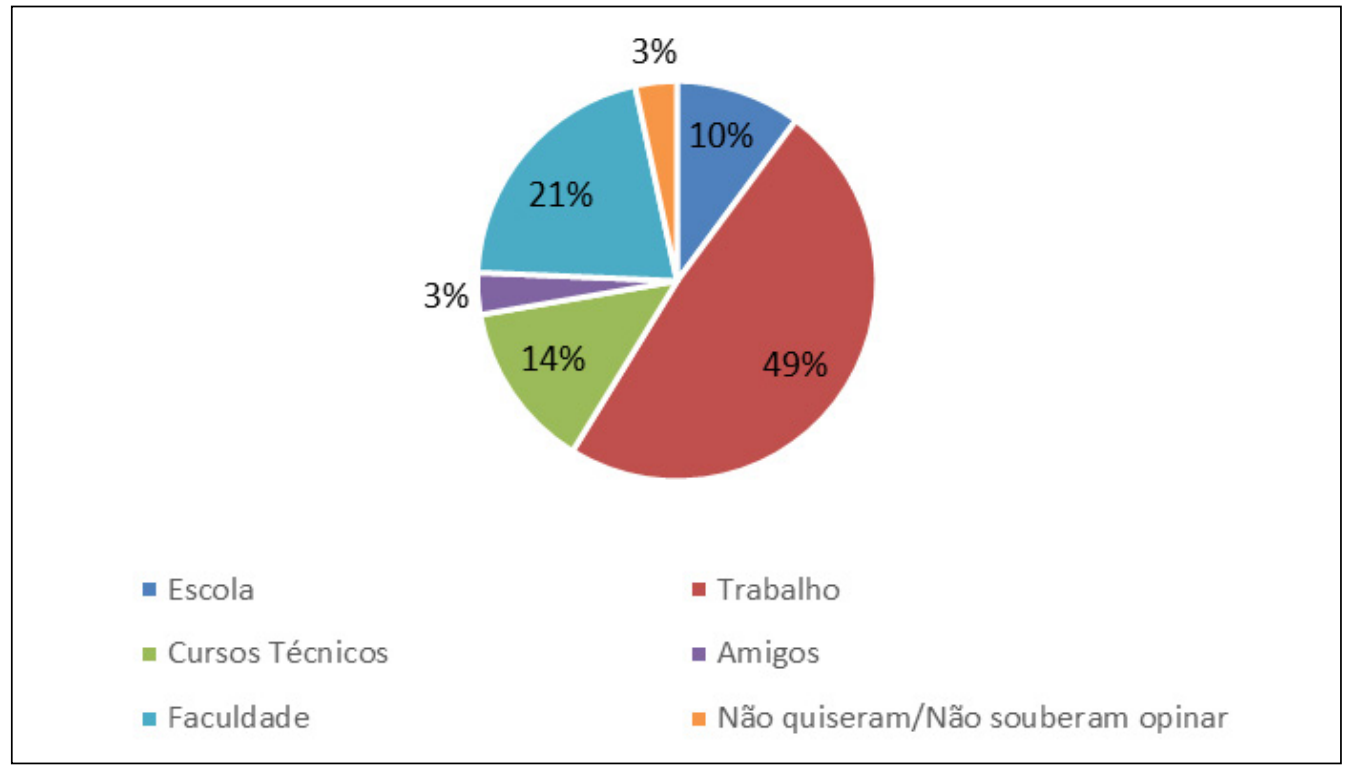

Fonte: dos autores.

Os pesquisados foram questionados sobre o conhecimento ou não do orçamento familiar por parte de seus filhos. A Tabela 5 aponta que $54,95 \%$ dos filhos das famílias pesquisadas não conhecem o orçamento familiar e 45,05\% conhecem. Observa-se que as famílias ainda estão divididas em compartilhar ou não com seus filhos o orçamento familiar, o que já é um grande avanço, uma vez que em um passado pouco distante o orçamento familiar ficava restrito aos pais, os filhos não tomavam conhecimento das finanças familiares.

Tabela 5 - Seu(s) filho(s) conhece(m) o orçamento familiar?

\begin{tabular}{lccc}
\hline & Frequência & Porcentagem & Porcentagem Acumulada \\
\hline Sim & 50 & $45,05 \%$ & $45,05 \%$ \\
Não & 61 & $54,95 \%$ & $100,00 \%$ \\
\hline TOTAL & $\mathbf{1 1 1}$ & $\mathbf{1 0 0 , 0 0 \%}$ & \\
\hline
\end{tabular}

Fonte: dos autores.

Para Kiosaki (2002), a educação financeira deveria ser ensinada desde os primeiros anos de vida da criança. Para os casos em que a família não tenha este conhecimento para transmitir para seus filhos, a educação financeira deveria ser passada nas escolas, desde a educação fundamental, uma vez que são poucas e insuficientes as iniciativas nesta área. E, o que se vê em tempos 
atuais é que as pessoas de diversas faixas etárias estão tendo dificuldades com as suas finanças.

Segundo Stehling e Araújo (2008), a educação financeira deveria ser prioridade na educação de nossas crianças, e iniciada o mais cedo possível para que se adquira uma relação saudável com o dinheiro, a fim de conquistar a independência econômica e ter consciência da utilização do dinheiro no dia a dia.

Na pergunta seguinte, foi analisado se as famílias entrevistadas consideram importante que seus filhos aprendam sobre educação financeira. Nessa, 100\% dos respondentes afirmaram que Sim. Neste quesito, com relação à resposta dos respondentes, percebe-se a importância do tema e como as famílias estão evoluindo e se adequando aos tempos atuais.

Quando questionados sobre quem deve ensinar seus filhos sobre educação financeira, $81 \%$ dos respondentes afirmaram que a responsabilidade sobre a educação de seus filhos é das Famílias e das Escolas em conjunto. 14\% responderam que é da Família (Pai e/ou Mãe), 3\% que é da escola e 2\% que devem aprender por conta, conforme o Gráfico 3.

Gráfico 3 - Quem deve ensinar sobre educação financeira
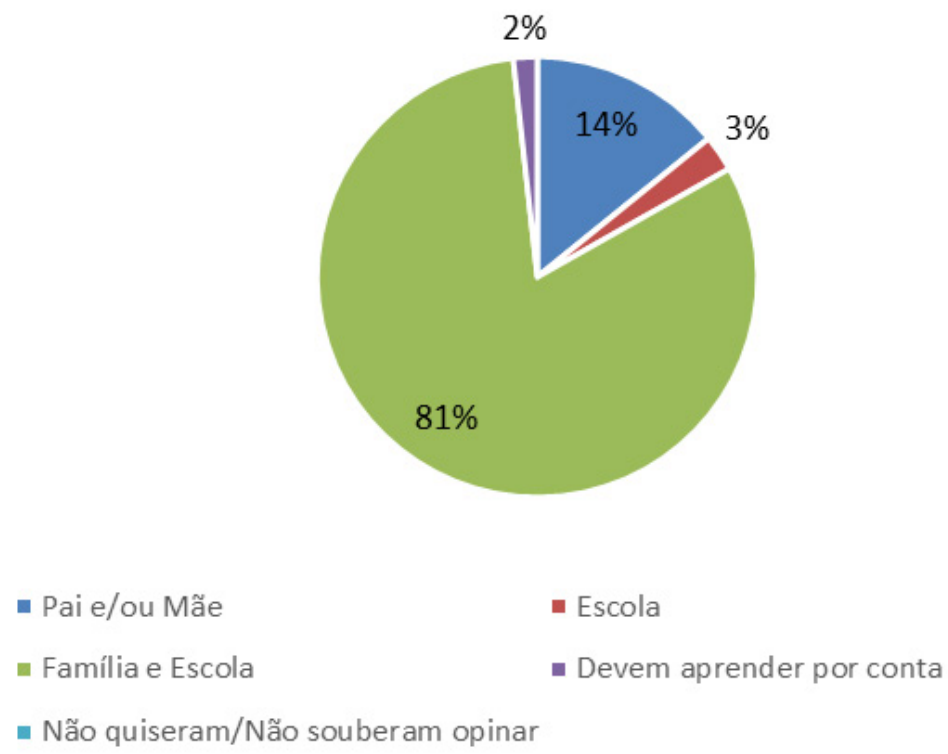

Fonte: dos autores.

Conforme Borges (2013), no Brasil, a educação financeira não tem caráter curricular nas escolas de educação básica até as universidades, diferente de outros países como os Estados Unidos e o Reino Unido, onde a educação 
financeira é difundida nas escolas de ensino médio e universidades, de acordo com Aviz (2009).

Os respondentes foram questionados se seu(s) filho(s) recebe(m) mesada. E diante da questão $73,87 \%$ informaram que não e $26,13 \%$ que sim, conforme a Tabela 6.

Tabela 6 - Seu(s) filho(s) recebe(m) mesada?

\begin{tabular}{lccc}
\hline & Frequência & Porcentagem & Porcentagem Acumulada \\
\hline Sim & 29 & $26,13 \%$ & $26,13 \%$ \\
Não & 82 & $73,87 \%$ & $100,00 \%$ \\
\hline TOTAL & $\mathbf{1 1 1}$ & $\mathbf{1 0 0 , 0 0} \%$ & \\
\hline
\end{tabular}

Fonte: dos autores.

Para Cerbasi (2006), a mesada e a semanada não são presentes, mas ferramentas de educação financeira. A criança deve entender desde o princípio sobre a responsabilidade de gerir e decidir sobre o dinheiro que recebe. Os pais devem permanecer atentos para a interpretação da mesada ou semanada, para que no caso de entendimento equivocado por parte de seus filhos, esta ferramenta seja descartada.

Dos pesquisados que responderam Sim, questionou-se qual a frequência com que pagam a mesada aos seus filhos e $75,86 \%$ responderam mensalmente e $24,14 \%$ semanalmente, o que pode ser observado na Tabela 7 .

Tabela 7 - Qual a frequência que seu filho recebe mesada

\begin{tabular}{lccc}
\hline & Frequência & Porcentagem & Porcentagem Acumulada \\
\hline Semanalmente & 7 & $24,14 \%$ & $24,14 \%$ \\
Mensalmente & 22 & $75,86 \%$ & $100,00 \%$ \\
\hline TOTAL & $\mathbf{2 9}$ & $\mathbf{1 0 0 , 0 0} \%$ & \\
\hline
\end{tabular}

Fonte: dos autores.

As famílias foram questionadas, ainda, sobre a importância da mesada para o planejamento financeiro de seus filhos. A Tabela 8 ilustra que 77,48\% dos respondentes afirmaram que entendem que a mesada é importante para o planejamento financeiro de seus filhos. Neste quesito, observa-se que mesmo com apenas $26,13 \%$ dos pesquisados que pagam mesada aos seus filhos, por motivos alheios, $77,48 \%$ entendem que a mesada é um meio importante para o planejamento financeiro de seus filhos. 
Tabela 8 - A mesada é importante para o planejamento financeiro de seu filho?

\begin{tabular}{lccc}
\hline & Frequência & Porcentagem & Porcentagem Acumulada \\
\hline Sim & 86 & $77,48 \%$ & $77,48 \%$ \\
Não & 22 & $19,82 \%$ & $97,30 \%$ \\
Não respondeu & 3 & $2,70 \%$ & $100,00 \%$ \\
\hline TOTAL & $\mathbf{1 1 1}$ & $\mathbf{1 0 0 , 0 0 \%}$ & \\
\hline
\end{tabular}

Fonte: dos autores.

\subsection{Planejamento Financeiro e Educação Previdenciária}

Segundo Frezatti (2009), planejar possibilita corrigir a vulnerabilidade antes do início da execução de uma tarefa, o que propicia a chegada a um objetivo pretendido de maneira eficiente. $\mathrm{O}$ autor enfatiza que o planejamento é uma necessidade intrínseca, é como se alimentar, para o ser humano, caso o indivíduo não se alimente, ele enfraquece.

Para Hoji (2004), o planejamento financeiro se evidencia quando se trata da forma de administrar o dinheiro, em que se pode fazer um controle de entradas e saídas através de um orçamento que aplicam métodos de planejamento financeiro.

A terceira seção de questões refere-se ao planejamento financeiro e educação previdenciária, nela se buscou identificar, junto aos respondentes, se as famílias pesquisadas planejam o futuro financeiro de seus filhos e, nos casos positivos, em qual modalidade, e as perspectivas para o futuro financeiro dos estudantes com a aquisição de planos de previdência.

Foi pedido às famílias pesquisadas se elas consideram importante que as famílias façam um planejamento familiar. Todos os respondentes $(100 \%)$ responderam que sim. Em seguida foram questionadas se falam com seus filhos sobre planejamento financeiro. $83,78 \%$ das respondentes afirmaram que sim e $16,22 \%$ que não, conforme a Tabela 9.

Tabela 9 - Você fala com seu(s) filho(s) sobre planejamento financeiro?

\begin{tabular}{lccc}
\hline & Frequência & Porcentagem & Porcentagem Acumulada \\
\hline Sim & 93 & $83,78 \%$ & $83,78 \%$ \\
Não & 18 & $16,22 \%$ & $100,00 \%$ \\
\hline TOTAL & $\mathbf{1 1 1}$ & $\mathbf{1 0 0 , 0 0 \%}$ & \\
\hline
\end{tabular}

Fonte: dos autores. 
Em seguida, os respondentes foram questionados se planejam o futuro financeiro de seus filhos. $87,39 \%$ responderam que sim, enquanto que $12,61 \%$ responderam que não. Aos que responderam sim, foi perguntado em qual modalidade. O Gráfico 4 demonstra a preferência dos pesquisados. $54 \%$ planejam através de poupança, $21 \%$ em imóveis e $18 \%$ em planos de previdência privada. Os demais pesquisados aplicam em ações e fundos de investimento.

Gráfico 4: Você planeja o futuro financeiro de seu(s) filho(s) em qual modalidade?

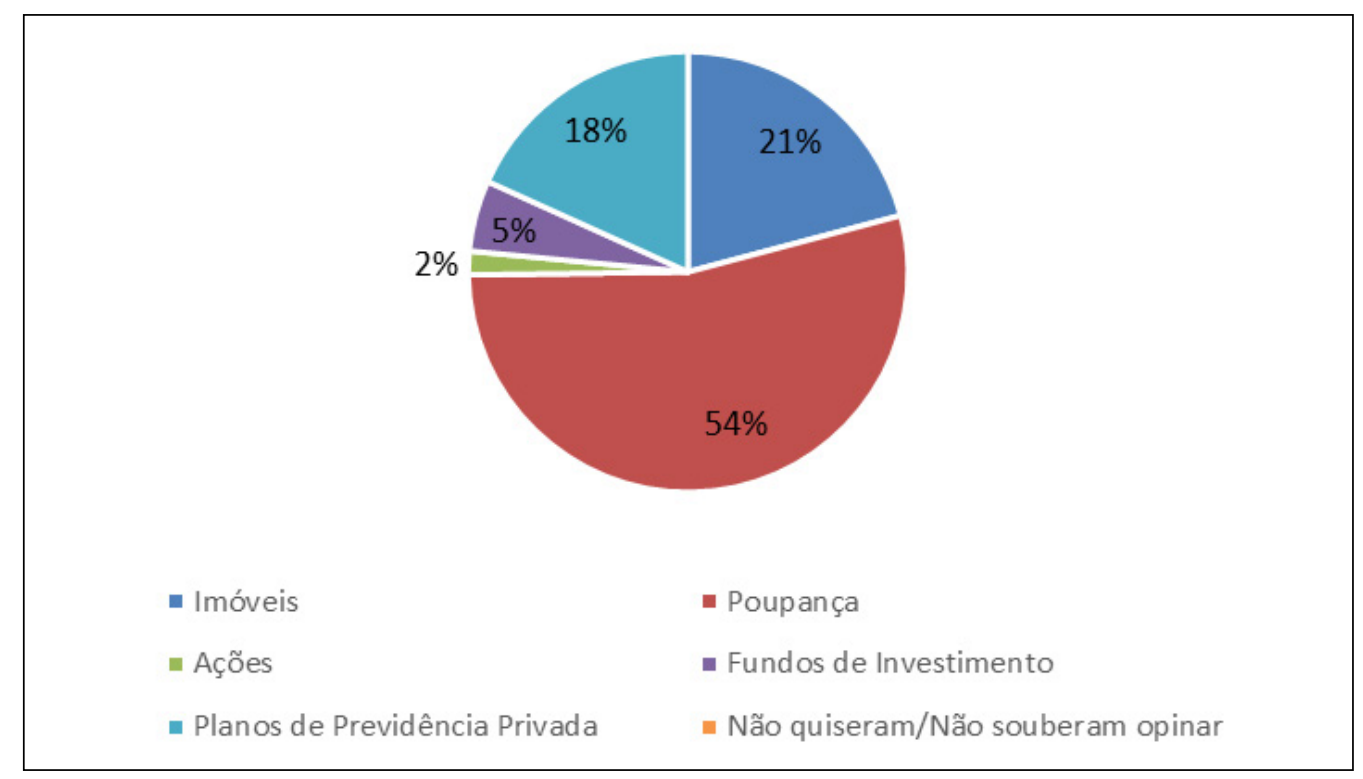

Fonte: dos autores.

Aos respondentes que informaram que não planejam o futuro financeiro de seu(s) filho(s) foi questionado qual modalidade lhes atrai mais. O Gráfico 5 demonstra a preferência dos respondentes, em que a poupança também foi a preferência com $44 \%$, seguida de imóveis e planos de previdência com $25 \%$ cada e $6 \%$ aplicaria em ações. 
Gráfico 5: Se você não planeja o futuro financeiro de seu filho, qual das modalidades lhe atrai mais?

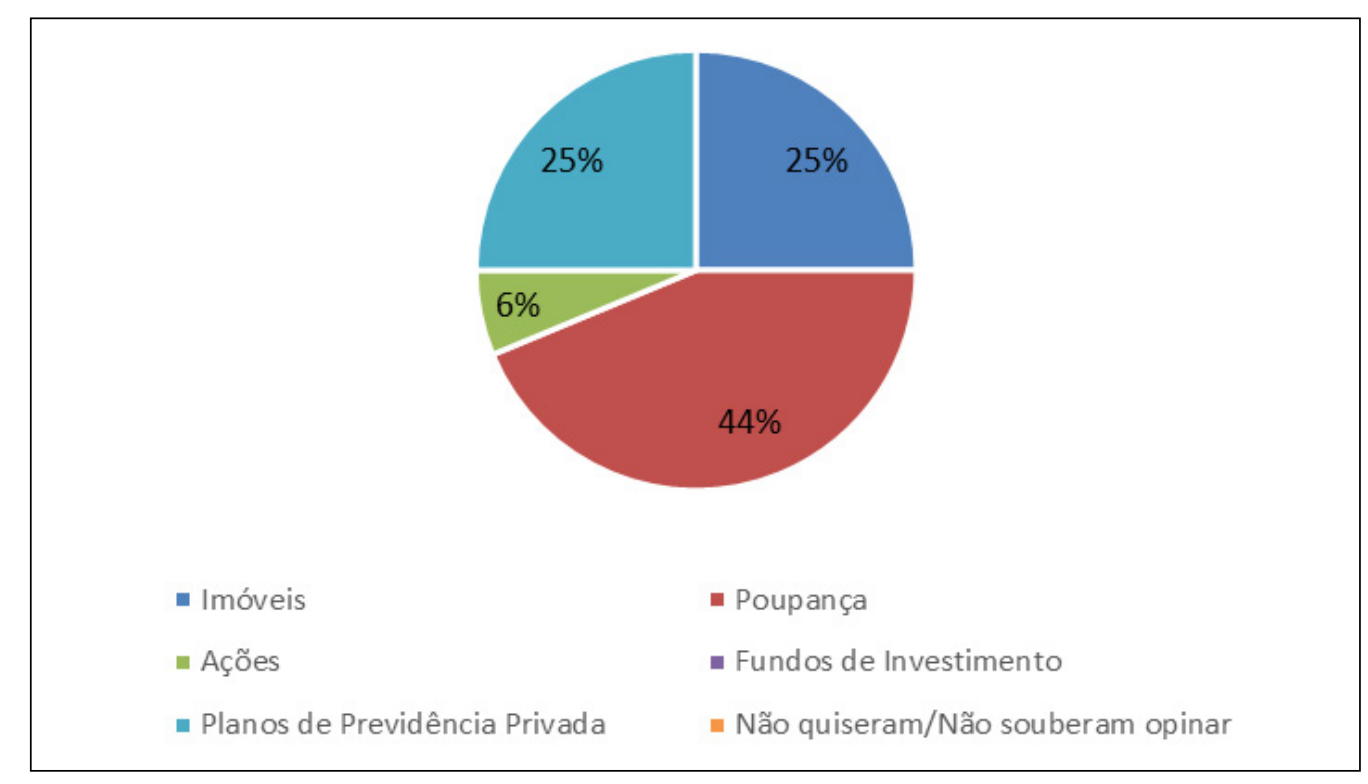

Fonte: dos autores.

Na sequência, os respondentes foram questionados da importância de se iniciar um planejamento financeiro para seus filhos desde a primeira infância, ou seja, desde os primeiros anos de vida da criança, 92,79\% responderam que sim e apenas $7,21 \%$ entendem não ser importante se iniciar um planejamento financeiro desde a primeira infância. Observa-se que as famílias estão cientes da importância de se iniciar bem cedo o planejamento financeiro de seus filhos.

Por fim, os pesquisados foram questionados sobre planos de previdência privada em uma escala de 1 a 5, em que 1 representa não possui conhecimentos em finanças e 5 representa possuo sólidos conhecimentos em finanças. A maior concentração de respostas foi 3 com $39 \%$, seguido pelo 2 com $26 \%$ e 3 com $25 \%$. O número 1 e o número 5 ficaram com $5 \%$ cada. O Gráfico 6 abaixo demonstra a opção dos respondentes. A média de conhecimento em planos de previdência privada dos respondentes ficou em 2,97. 
Gráfico 6: como você avalia o seu conhecimento sobre planos de previdência privada?

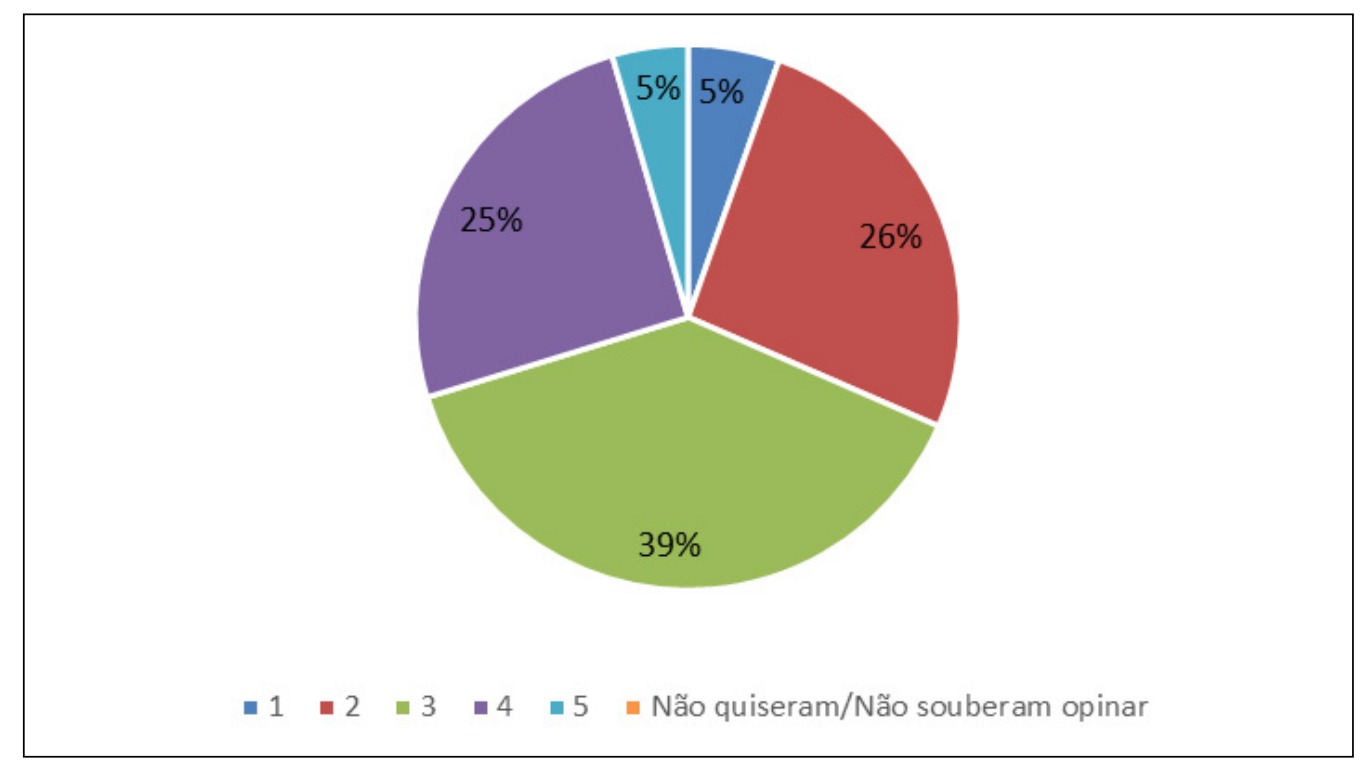

Fonte: dos autores.

Relatados os resultados da pesquisa, no próximo capítulo são apresentadas as conclusões deste artigo.

\section{CONCLUSÃO}

A educação financeira e o planejamento financeiro pessoal tornam as pessoas capazes de tomar decisões imprescindíveis para seu futuro financeiro. Com o desconhecimento sobre finanças pessoais e o acesso facilitado às linhas de crédito, o indivíduo fica vulnerável à aquisição de produtos e serviços inúteis e desnecessários para o seu dia a dia, aumentando seu endividamento e resultando no comprometimento das finanças pessoais.

O conhecimento sobre finanças pessoais faz com que os indivíduos administrem seus recursos e planejem seu futuro, para tornar seus sonhos realidade.

Diante disso, o objetivo desta pesquisa foi de identificar como os pais dos alunos do $1^{\circ}$ ao $9^{\circ}$ ano do Ensino Fundamental do Colégio Teutônia veem a importância do planejamento financeiro de seus filhos.

Em tempos atuais, com o desfavorável cenário macroeconômico de nosso país, que tem por consequência um alto índice de inflação e desemprego, as famílias tiveram que repensar suas atitudes e readequar suas finanças. As ações devem começar dentro de seus lares, para depois se adaptarem ao cenário econômico desfavorável. 
A partir dos resultados obtidos, verificou-se que os respondentes, independentemente do grau de escolaridade, da renda familiar e de seus conhecimentos sobre finanças, consideraram, em 100\% das respostas, que acham importante que as famílias façam um planejamento financeiro, e 83,78\% já falam com seus filhos sobre planejamento familiar.

Em contraponto, quando questionados se seus filhos conhecem o orçamento familiar, apenas $45,05 \%$ dos pesquisados confirmaram que seus filhos conhecem o orçamento da família. Conclui-se, então, que mesmo as famílias já estarem tratando com os seus filhos sobre planejamento familiar, menos de $50 \%$ dos respondentes discutem o orçamento de que a família dispõe.

Quando indagados sobre a mesada, $77 \%$ dos pesquisados entendem que a mesada é importante para o planejamento financeiro de seus filhos, contudo apenas $26,13 \%$ efetivamente pagam mesada. Observa-se que mesmo achando a mesada importante, um baixo índice de respondentes efetivamente aplica este método considerado importante para o planejamento financeiro de seus filhos.

Os respondentes foram questionados, ainda, se planejam o futuro financeiro de seus filhos e $87,39 \%$ respondeu que sim, tendo como principal modalidade a poupança, opção de mais de $50 \%$ dos pesquisados, seguida por imóveis, com $20,87 \%$ e após planos de previdência privada com $18,26 \%$.

Também foi questionada a importância de se iniciar o planejamento financeiro desde a primeira infância e $92,78 \%$ responderam que sim. Verifica-se que os pesquisados estão cientes da importância pensar e agir cada vez mais cedo no futuro de seus descendentes.

No questionamento sobre o conhecimento em planos de previdência privada, numa escala de 1 a 5 , a nota 3 prevaleceu com $38,74 \%$. Fica demonstrado que os planos de Previdência Privada que vem complementar a Previdência Oficial, ainda não são muito conhecidos pelo público pesquisado, com a média dos respondentes de 2,972\% que conhecem planos de previdência privada.

Desta forma, considera-se que o objetivo foi plenamente alcançado com a realização desta pesquisa. Como limitações do estudo ressalta-se que os resultados apresentados não podem ser generalizados, sendo válidos apenas para as famílias dos estudantes do Ensino Fundamental do Colégio Teutônia, comarca de Teutônia, no estado do Rio Grande do Sul.

Por fim, alguns tópicos podem ser levantados como sugestões para pesquisas futuras, a saber: pesquisa com os pais dos estudantes do ensino médio e cursos técnicos desta instituição de ensino a fim de comparar resultados; pesquisa com as famílias dos estudantes de outras escolas públicas e privadas do mesmo município, com o intuito de também comparar resultados. 


\section{REFERÊNCIAS}

ALMEIDA, R. R. Z. de. Análise das finanças pessoais: um estudo para acadêmicos do curso de Administração de Empresas da Universidade Feevale. 2010. Monografia (Graduação) - Curso de Administração de Empresas da Universidade Feevale. Novo Hamburgo.2010.

ANDRADE, M. M. de. Introdução à metodologia do trabalho científico: elaboração de trabalhos na graduação. São Paulo: atlas, 2003.

AVIZ, Christopher. Demandas de educação financeira pessoal no ensino médio público e privado do Distrito Federal. 2009. 61 f. Monografia (Graduação) - Curso de Administração, Universidade Nacional de Brasília, Brasília, 2009. Disponível em: <http://bdm.unb.br/bitstream/10483/771/1/2009_Christopher\%20Aviz.pdf>. Acesso: 20 set. 2015.

BARROS, A. J. da S; LEHFELD, N. A. de S. Fundamentos de metodologia científica: Um guia para iniciação científica. 2. ed. São Paulo: Pearson Education do Brasil, 2000.

BARROS, C. A. R. de. Educação financeira e endividamento. 2009. Monografia (Graduação) - Curso de Adminsitração, Escola Superior de Administração, Direito e Economia - ESADE, Porto Alegre, 2009.

BORGES, Paulo R. S. A influência da educação financeira pessoal nas decisões econômicas dos indivíduos. In Encontro de Produção Científica e Tecnológica. VIII EPCT 2013. Anais... Campo Mourão, 2013. Disponível em: <http:/ / www. fecilcam.br/nupem/anais_viii_epct/PDF/TRABALHOS-COMPLETO/Anais-CSA/ ECONOMICAS/04-Pborgestrabalhocompleto.pdf>. Acesso em: 27 set. 2015.

CERBASI, Gustavo. Filhos Inteligentes Enriquecem Sozinhos: como preparar seus filhos para lidar com o dinheiro. São Paulo: Editora Gente, 2006.

FOULKS, S.M.; GRACI, S.P. Guidelines for Personal Financial Planning. Business. Vol. 33, n.2; p. 32, 1989.

FREZATTI, Fábio. Orçamento empresarial: planejamento e controle gerencial. 5.ed.-2. Reimp. São Paulo: Atlas, 2009.

GADELHA, Kalyne Amara Di Lorenzo e LUCENA,Wenner Glaucio Lopes. Decisões Financeiras X Formação Acadêmica: uma contribuição com base na Educação Financeira. Revista de Administração e Negócios da Amazônia, V.7, n.1, jan/abri.2015.

GIANETTI, Eduardo. O valor do amanhã: ensaio sobre a natureza dos juros. São Paulo. Companhia das Letras. 2005.

GIL, A.C. Como elaborar projetos de pesquisa. 4 ed. São Paulo: Atlas, 2002.

GITMAN, Lawrence J. Princípios de Administração Financeira. 12. ed. São Paulo. Pearson Prentice Hall, 2010. 
GREESNSPAN, A. Financial Literacy: A Tool for Economic Progress. The Futurist, v.36, n.4, p.37-41, July-Aug. 2002.

HOJI, Marakazu. Administração Financeira na prática: guia pra educação financeira corporativa e gestão financeira pessoal. São Paulo: Atlas, 2004.

KIYOSAKI, R. 2002. Independência Financeira. Editora Elsevier, Rio de Janeiro.

LUXO, José Carlos. Aprenda a viver melhor mantendo a saúde financeira do seu bolso. Universidade Banco do Brasil, 2016.

LEMES JÚNIOR, Antônio Barbosa, CHEROBIM, Ana Paula Mussi Szabo e RIGO, Cláudio Miessa. Administração Financeira: Princípios, Fundamentos e Práticas Brasileiras. Editora Campus, 2002.

MALHOTRA, N. Pesquisa de marketing: uma orientação aplicada. $3^{\mathbf{a}}$ ed. Porto Alegre: Bookman, 2001.

MARCONI, M. de A.; LAKATOS, E.M. Técnicas de Pesquisa: Planejamento e execução de pesquisas, Amostras e técnicas de pesquisa, Elaboração, análise e interpretação de dados. São Paulo: Atlas, 2002.

MATSUMOTO, Alberto Sheguru, NEVES JÚNIOR, Idalberto José, BOURAHLI, Abdelkader e CARREIRO, Luiz Carlos. Finanças Pessoais: um estudo sobre a importância do planejamento financeiro pessoal. Florianópolis, 2013.

NIQUE, Walter; LADDEIRA, Wagner. Pesquisa de marketing: uma orientação para o mercado brasileiro. São Paulo: Atlas, 2014.

ORIENTAÇÃO FINANCEIRA EM NEGÓCIOS BANCÁRIOS. Universidade Banco do Brasil. Disponível em : <www.unibb.com.br>.

PINHEIRO, Ricardo Pena. Educação financeira e previdenciária, a nova fronteira dos fundos de pensão, 2008. In: INSTITUTO SANTIAGO DANTA DE DIREITO E ECONOMIA. Fundos de Pensão e Mercado de Capitais. São Paulo: Peixoto Neto, 2008. Disponível em : <http:/ / www.previcencia.gov.br/arquivos / office/3_090420-113416-244.pdf.

ROSS, S.; WESTERFIELD, R.; JAFFE, J. F. Administração financeira. São Paulo: Atlas, SERASA EXPERIAN. Disponível em : <https:// www.serasaexperian.com.br>.

SEVERINO, Antônio Joaquim. Metodologia do trabalho científico. 23.ed. ver. Atual. São Paulo: Cortez, 2007

STEHLING, Priscilla e ARAÚJO, Meire. Alfabetização Financeira. Revista da Escola Adventista. São Paulo, 2008. 
WESTON, J. Fred e BRIGHAM, Eugene F. Fundamentos da administração financeira. São Paulo: Makron Books, 2000.

ZENKNER, D. Finanças pessoais: uma análise da gestão financeira das famílias com renda acima de 10 salários mínimos do munícipio de Lajeado. 2012. Monografia (Graduação) - Curso de Administração, Centro Universitário UNIVATES, Lajeado, 2012. 